\title{
Arms Control Arrangements under the Aegis of the OSCE: Is There a Better Way to Handle Compliance?
}

\section{Pál Dunay}

George C. Marshall European Center for Security Studies, http://www.marshallcenter.org

\begin{abstract}
The CSCE-OSCE has strong legacy in conventional arms control both as far as limitations and reductions and constraints on military activities. Although the last two decades since 1999 did not add much to the arms control acquis and there was a "retreat" in arms control with the suspension of the CFE Treaty. It is Germany that keeps European conventional arms control on the agenda as part of security dialogue since the Harmel Report of 1967 and takes symbolic initiatives as a demonstration. Although compliance is not full and some activities demonstrate the intention to cheat, their level is more important as part of the communication of the main parties rather than of direct strategic significance.
\end{abstract}

Keywords: Arms Control, CFE, compliance, CSBMs, European Security, military exercises, Open Skies Treaty, verification.

\section{Preliminary Assumptions}

- Arms control, including conventional arms control, does not constitute an end in itself and can be seen as the outward military/technical manifestation of the inward international political climate. ${ }^{1}$

- If conventional arms control works best in an environment, which is neither characterized by animosity nor by full mutual trust, the current European situation is favorable to it. In the case of the former, arms control is

1 Desmond Bowen, "Restoring Peace, Security, and Stability in Europe - What Role for Arms Control?" (London: October 2014, manuscript). 
impossible; in the case of the latter, it is not necessary. However, as the European conventional arms control arrangements agreed between 1990 and 1994 have demonstrated, the relationships must be closer to mutual trust than to limited animosity if success is to be achieved. This requires a further qualification of the previous assumption.

- Success in conventional arms control is frequently identified with the conclusion of agreements. However, this is an arbitrarily narrow definition of the concept. Making established conventional arms control implementation fora work, transparency, compliance and, if necessary, enforcement of obligations form part and parcel of arms control. It is more of a process than a series of distinct points.

- Conventional arms control and confidence- and security-building measures (CSBMs) have been separated from and contrasted with each other by the participating states of the Organization for Security and Cooperation in Europe (OSCE). This is contrary to common sense and the observation of analysts who prefer to differentiate between structural and operational arms control. ${ }^{2}$

- Since the fundamental rearrangement of the geopolitical landscape and power relations in Europe, associated with the end of the Cold War and the subsequent winding up of the Warsaw Treaty and the enlargement of NATO, no adaptation has taken place in European (Euro-Atlantic) arms control that is in force.

\section{Characteristic Features of the Current Situation}

The security perception of European states and their citizens, particularly the overwhelming majority that confined its interests regionally, has improved during the quarter of a century since the end of the Cold War and the middle of the current decade. Not even the wars in the former Yugoslavia, the protracted conflicts in the former Soviet Union, the secession of Abkhazia and South Ossetia and the annexation of Crimea could reverse this perception. However, these protracted conflicts have undermined the achievement of new accords, be they documents approved by OSCE Ministerial Councils, the Astana Summit, or a more extensive modernization of the CSBM package.

Whereas for some participating states a significant deterioration of the security situation started in 2008, for many others the sea change occurred in 2014. Again, for some other participating states the deterioration of relations began with the so-called Kosovo war of 1999 and was followed by the Iraq war of 2003 (both without approval by the UN Security Council). However, it would be difficult to argue for them to be seen as turning points because relations re-

2 Richard E. Darilek, "The Future of Conventional Arms Control in Europe, a Tale of Two Cities," in SIPRI Yearbook 1987: World Armaments and Disarmament (Oxford: Oxford University Press, 1987), 339-354. 
turned to cooperation later. It is certain that relations between Russia and the West have, with significant variations, reached a new low since 2014. This means that the external conditions for agreeing upon measures based on cooperation are not favorable. At least one of the current conflicts, in Ukraine, carries the danger of qualifying as 'protracted' and thus further increases the prospect of more such conflicts. Political establishments in different capitals have interpreted this conflict in different ways. Hence, it may still be possible to have working relations irrespective of some violations at the top level in the hierarchy of international law.

Some participating states are of the view that a rule based international order cannot exist when there are prima faciae violations of its foundations such as the territorial integrity or the political independence of states. Whereas a change of territorial integrity can be easily attributed to external players, others emphasize the undermining of the political independence of countries by externally induced or actively supported measures, like the so-called color revolutions. Those universal, peremptory norms cannot be disregarded with reference to claims be they founded on history, ethnic composition or the right to self-determination. This is independent of whether any OSCE document reaffirms the norm or not. If this approach is interpreted strictly, no business can be made between states that violate either of those norms. As it is highly unlikely that some change could be reversed this would lastingly freeze relations. Even if this view starts out from the integrity of the international legal order and thus has internal logic, it is not realistic to assume that this would be, generally, in the long-term interest of the participating states. Other participating states tacitly recognize the potentially detrimental consequences of such an approach and emphasize the importance of maintaining relations, including security matters, among the OSCE. This view can be further differentiated according to the emphasis made in overcoming the stalemate and covering the gaps. They can be grouped as follows:

- Top down approach. Cooperation is impossible as long as a violation of basic international legal principles continues;

- Bottom up approach. Cooperation in select areas must be possible irrespective of violations on other levels;

- Opening a new chapter. Create distance between the eventual noncompliance with the arms control arrangements and the gross violation of the European peace order, and the stalemate in discussing/negotiating/agreeing upon new measures and hence make the coexistence of the current situation and the opening of a new chapter possible.

The various positions go back to the assumption of how the current tension can be overcome - (re)creating a cooperative environment in which the perpetrator could react constructively. The "top down approach" has been identified 
with particular emphasis upon deterrence. However, the term deterrence does not bring us close to an accurate assessment of the purposeful line to be taken. It is much more of a roll-back policy that requires the state that annexed and seized territory to give up and return to the status quo ante. Irrespective of how desirable this might be, it is hardly realistic to count on or expect such a development. This results in a certain kind of 'doubletalk' ${ }^{3}$ as the participating states actually know there will be no such return. However, they use it as part of their strategic communication and will only be ready to sacrifice it for some compensation. This leads to a gradual increase in the number of protracted conflicts, lasting stalemates and a crisis of classical diplomacy where every constructive step is a concession.

The bottom up approach addresses 'technical' arms control matters irrespective of problems on levels closer to high politics. This could make technical discussions possible on areas such as compliance and could fill the agenda of fora established to address implementation.

The most constructive (or apparently constructive) approach is the one that separates the implementation of commitments from constructive arms control dialogue among the participating states irrespective of their current compliance record. Here, the smaller technical violations of living up to detailed commitments under arms control arrangements are not the problem; it is the larger violations that evaporate trust and confidence. This third option seems more preferable as arms control can be regarded as "a means to build trust where it has been lost" under the assumption that irrespective of how "deep the rifts, we must try to build bridges." ${ }^{4}$ This was followed by that the incoming OSCE Troika took the commitment "to launching a structured dialogue on security and arms control" - apparently an achievement of the outgoing German chairmanship. ${ }^{5}$ The structural dialogue has started and certainly contributed to professional exchanges of experts in spite of the fundamental disagreements on major European security issues that were impossible to overcome.

Those who belong to the first group regard this as the indication of a policy of appeasement without offering the alternative of moving the situation out of the stalemate. Some other authorities are of the view that such an initiative undermines the efforts of NATO members to improve transparency and guarantee compliance. ${ }^{6}$

3 Gerard C. Smith, Doubletalk: The Story of the First Strategic Arms Limitation Talks (Garden City, NY: Doubleday, 1980).

4 Frank-Walter Steinmeier, "Reviving Arms Control in Europe," Project Syndicate, August 26, 2016, https://www.project-syndicate.org/commentary/reviving-armscontrol-in-europe-by-frank-walter-steinmeier-2016-08.

5 OSCE Twenty-Third Meeting of the Ministerial Council 8 and 9 December 2016, Hamburg Declaration of the Incoming OSCE Troika: A Strong OSCE for a Secure Europe, MC.GAL/11/16, December 9, 2016, www.osce.org/chairmanship/307311.

6 Justyna Gotkowska, "The German Initiative for Arms Control: Time for Dialogue with Russia," Ośrodek Studiów Wschodnich, September 9, 2016, www.osw.waw.pl/ print/24646. 
It is clear that the difference between the various groups is gradual. In fact, no state wants to arrive at a situation that contributes to antagonistic opposition. It is more a question of which areas could be exempted in order to continue to foster cooperation. It might be confined to those areas in which the declared adversary has something indispensable to offer, like nuclear weapons, countering terrorism, or in certain local conflicts. The fact that European arms control does not fit into this category limits the freedom of cooperation among the participating states. However, not attributing more importance to conventional arms control partly fits with the agenda of some participating states. They seem to prefer some rebalancing between various dimensions of the OSCE, thereby attributing more importance to the politico-military dimension on the agenda of the OSCE and relegating arms control to one of its important topics. However, such a 'rebalancing' between different dimensions has already taken place due to increased attention being paid to some conflicts, predominantly on the territory of Ukraine. Indeed, no state going through largescale modernization of its armed forces (that is not confined to the replacement of armaments and equipment by a new generation of weapons), but also entails the need to carrying out significantly more military exercises, would likely be monitored closely. Consequently, in this phase it is, understandably, not interested in more transparency.

The idea to develop so-called 'status neutral' arms control has been discussed for some time. It appeared, and gained some popularity, in the context of post-2008 Georgia. ${ }^{7}$ This was because the challenge to the territorial integrity of the South Caucasian state and the Russian recognition of the statehood of its two separatist entities required a highly innovative approach to avoid a full arms control blockade. However, despite the frantic efforts of diplomats and scholars, the concept did not get very far. Difficulties arise whenever contested states are obliged to provide information about their armaments and military activities. When they carry out on-site inspections or host outside observers, it is impossible to overcome the problem of which country has the sovereign right to order or give permission for these inspections. It is for this reason that status neutral arms control rapidly clashes with status related matters and can only work alongside political solutions for the status of contested territories. Consequently, as status neutral arms control did not achieve much in the recent past, it is unlikely that it will in the foreseeable future either.

In light of the changed security landscape, analysts started to take a fresh look and were critical of those many actors "in Berlin apply a Cold War ap-

7 Sergi Kapanadze, Ulrich Kühn, Wolfgang Richter, and Wolfgang Zellner, "Status-Neutral Security, Confidence-Building and Arms Control Measures in the Georgian Context," Working Paper 28 (Hamburg: The Centre for OSCE Research (CORE), January 2017), https://ifsh.de/file-CORE/documents/Working_Papers/CORE_WP28_en_.pdf. 
proach to arms control that no longer suits" the new security environment. ${ }^{8}$ Innovative approaches of analysts, opening avenues in arms control that have been attempted a number of times, like addressing technological innovations and quality of forces, pop up again. However, some major powers neither intend to discuss arms control formally based on the old agenda, nor want they to change it for an unexplored one.

\section{The Compliance Record}

OSCE-related arms control, be it structural or operational, has occasionally attempted to be enriched by elements other than the "Holy Trinity" of The Treaty on Conventional Armed Forces (CFE), Confidence- and Security-Building Measures (CSBMs) and The Open Skies Treaty. However, in terms of visibility it has remained unsuccessful because the political leadership of the participating states has continued to identify European arms control with those three sets of documents. Consequently, the compliance record is based primarily on their implementation.

The sparse literature and official documents give testimony to the fact that the number and significance of violations do not give reason for large-scale strategic concerns. Although they indicate that some parties do not intend to comply fully with their commitments, concerns related to non-compliance can be interpreted as more worrisome in the light of broader international concerns that stem from the systematic violations of the basic principles of international law. They occur in areas that are associated with the use of force by OSCE participating states. A deteriorating atmosphere and the consequent loss of trust is the result. Where non-compliance with the letter of legally or politically binding agreements cannot be substantiated, states move to the violation of their spirit. When they cannot prove the former, states create a revolving door and they challenge their partners on the latter. As every major party plays this not at all innocent game, each mix fairly strong claims with rather weak ones (substantiated stricto sensu violation by the other party mixed with behavior that may not fit entirely with the spirit although cannot be challenged on the letter of the accord).

As far as the CFE Treaty and its adaptation agreement are concerned, the situation is clear. The operation of the original treaty, signed in November 1990 and brought into force in 1992, was suspended in 2007 by Russia and, after a long period of hesitation, members of the Atlantic Alliance also stopped sharing information. Delegates, according to their instruction, will not have to agree about the legality of the suspension. However, in concord with the letter of the treaty based on the Roman law dictum "argumentum a maiori ad minus" (Who has the right to the more, has the right to the less) the legality of this action can

8 Claudia Major and Christian Mölling, "How Germany Should Change Its Approach to Arms Control," Carnegie Europe, accessed September 7, 2017, http://carnegieeurope.eu/strategiceurope/73031. 
hardly be denied. The adaptation agreement has not entered into force and thus the obligations of the parties have never exceeded those under a signed but not ratified treaty. (Confined to: "Not to violate the object and purpose of the treaty.") The sustained position of the suspending party was demonstrated by its interpretative statement made at the Hamburg meeting of OSCE foreign ministers and extensive comments of the Russian foreign minister on the topic. There, Sergey Lavrov called the attention to the fundamental change of circumstances in the strategic landscape (non-ratification of the CFE adaptation agreement by NATO members for ten years, the enlargement of NATO and the extension of alliance infrastructure to the vicinity of the Russian Federation). Indirectly Russia has excluded to return to discussing conventional arms limitations. ${ }^{9}$ Regrettable though this may be politically, and detrimental strategically, there is no reason to involve the CFE with the compliance record as there is no legal commitment against which it could be examined. In light of this, the compliance record should be measured on the basis of the Vienna Document (VD) and the Open Skies Treaty.

It is noticeable though that non-compliance cases cannot be confined to the state party that suspended the CFE Treaty but also should include some states, that are engaged in sub-regional military rivalry in the South Caucasus. However, this attracts less attention as the CFE regime does not function.

Different participating States are, to some extent, transparent about compliance with conventional arms control, including the VD and the Open Skies Treaty. Furthermore, when going public, they understandably provide more information about other countries that are not their allies or close friends. Consequently, it is difficult to develop a comprehensive and reliable picture about compliance and eventual violations. However, cases of non-compliance can be divided into three groups:

1. Non-compliance during conflict and due to the change of the territorial status quo

2. Non-compliance associated with protracted conflicts

3. Insufficient transparency and other violations.

\section{Compliance with the Vienna Document}

Since the Stockholm breakthrough of 1986, Confidence- and Security-Building Measures (CSBM) have developed significantly. However, there are still many measures that address the security concerns that dominated the Cold War agenda, like rapid mobilization, concentration of forces for surprise attack, practicing offensive actions at exercises, which may need to be applied in the

9 Foreign Minister Sergey Lavrov's statement and answers to media questions at a news conference following the 23rd OSCE Ministerial Council meeting, Hamburg, December 9, 2016, http://www.mid.ru/en/press_service/minister_speeches//asset_publisher/7OvQR5KJWVmR/content/id/2556212. 
future or, in the case of large-scale ones, could immediately evolve into them. The end of the Cold War modernization of the CSBM packages addressed strategic ambiguity by introducing risk reduction, including the procedures in case of so-called unusual military activity. It also recognized the growing importance of mobility when it introduced visits to air bases. The 1999 package was the most important in that it recognized that the security needs of different parts of the OSCE area may vary and hence different measures may be relevant, agreed and applicable.

The most important weaknesses of the Vienna Document, in all its variations, are as follows:

- Crisis related weaknesses, such as the fair-weather character of the document that results in ineffectiveness (though not inapplicability) during conflicts

- Contextual weaknesses in terms of the inability to avoid the artificial linkages with other political divergences, like protracted conflicts

- Early warning/prevention weaknesses related to too high and/or obsolete thresholds. ${ }^{10}$

Even though the first and second points may be closely linked, the three points above provide a focused overview of the VD's main shortcomings and weaknesses. Some measures tend to regain their relevance and cause concerns under current conditions again. The level of force concentration, once addressed by CSBMs, has declined and no participating state, nowadays, carries out many exercises on a scale that would make mandatory long-term advance announcement necessary and require the invitation of observers. Moreover, participating states with the largest armed forces (the United States, the Russian Federation and Turkey) among the 57, have the possibility to conduct exercises on their own territory, which is outside of the area of application of the Vienna Document.

The exercise program of states in the area of application are also used for public diplomacy, propaganda and have been made part of blaming games. It is sufficient to mention the Russian-Belarus exercise, Zapad-2017 and the attempts to create various impressions around it. The western image focused on the strategic significance of the exercise, contextualizing it around the neighborhood of Ukraine and the size of the exercise in the vicinity of NATO member-states, adjacent to Belarus. Even experts tended to speak about the largest ever exercise since the end of the Cold War, a statement that would have been difficult to substantiate by facts. The Russian Federation, on its side, was not tempted to contribute to transparency and supplied data on the number of troops and vehicles involved in the exercise that seemed to have been deliber-

10 Iztok Prezelj and Daniel Harangozo, "Effectiveness of the Vienna Document CSBM Regime: Assessment of Experts' Perceptions," OSCE Network (Ljubljana: University of Ljubljana, Faculty of Social Sciences, Defence Research Centre, 2014). 
ately reduced to less than $13^{\prime} 000$ soldiers, the level that would have required the implementation of the mechanism for observation of exercises provided for in the Vienna CSBM Document. This meant that the politicization of the matter resulted in its contribution to political discourses and thus deprived it of its core military professional content. ${ }^{11}$

When the status of a territory changes between two states without their mutual agreement, it often entails the employment of military force in one form or the other. Bearing in mind the nature of such an operation and the unconditional prohibition of the use of force under international law, no state would use military force openly. During the high intensity phase of such a conflict, the threshold of notifiable and observable activities may be violated. Later, various methods might be applied to reduce the availability of accurate information.

As far as rules of the Vienna Document are concerned, the following methods are applied in such situations:

- Resubordination of personnel, armaments and equipment so that their activities would not be subject to notification and observation. This method has a long-standing history in arms control and the violations that have occurred on a larger scale in the past.

- In this context, sometimes troops and forces have been mobilized that are subordinated to different commands so that the individual units that are activated for an exercise do not reach the threshold of notification and observation individually. Hence, the figures, if communicated at all, are shared as a goodwill gesture only. Goodwill gestures may alleviate concerns. However, they are easy to ignore or revoke. In other cases, some activities may reach the notifiable level but not the level subject to observation. It can be stated that the thresholds are too high particularly when taking into consideration increased mobility, connectivity and units capable of cross-border combat from their permanent peacetime location including boundaries with de facto states. ${ }^{12}$

- It is more difficult for a state to legitimize the non-provision of data on armed forces when they are in an area that it has declared unilaterally to be under its sovereignty. Sovereignty, irrespective of whether other participating states recognize it, is accompanied by responsibility. It is objective and, hence, the participating state cannot be in breach of its

11 For an example see: Andrzej Wilk, "The Zapad-2017 exercises: the information war (for now)," OSW Commentary, accessed September 4, 2017, https://www.osw.waw.pl/en/publikacje/osw-commentary/2017-09-04/zapad-2017exercises-information-war-now.

12 Gregory G. Govan, "Conventional Arms Control in Europe: Some Thoughts About an Uncertain Future," Deep Cuts Issue Brief \#5 (July 2015), http://deepcuts.org/files/ pdf/Deep_Cuts_Issue_Brief5_Conventional_Arms_Control_in_Europe\%281\%29.pdf. 
obligations. When a state's government declares a change in its national territory, the argument for not notifying the size of its armed forces occupying the new territory is void unless it is below the limit and hence not subject to notification. However, other states, which do not recognize such a change, could face a delicate situation when demanding notification from the state that has, according to their opinion, annexed a territory belonging to another participating state. This could result in a situation in which the participating state, a part of whose territory has been annexed by another, may continue to provide information about forces on the territory that it claims to be its own.

- It defeats the object and purpose of confidence- and security-building if a state simply denies that its forces are present on the territory of another. It has the effect of eroding confidence irrespective of whether the number of troops, their equipment and activity exceed the notifiable level. In the light of such a denial, no risk reduction measure is applicable and no question can be raised concerning unusual military activity as it clashes with the denial. An arms control regime that starts out from the principle that participating states are honest about their military capabilities, the location of their troops and their military activities cannot manage such a situation.

The phenomenon of so-called protracted conflicts presents other challenges than the territorial conflicts that are still in the active phase. Although some conflicts outlined above carry the danger to morph into protracted conflicts, it would present a philosophical problem to speak about a potentially protracted conflict. How long a time period should pass before we may safely conclude that a conflict is protracted? It presents a further problem that some so-called protracted conflicts have arrived at a new status quo whereas others continue to threaten with volatility and their moving from a 'frozen' phase to one of high intensity.

The existence of de facto states, statelets, or pseudo-states, as different authors call them, presents a problem as they are sovereign entities without sufficiently wide-ranging international recognition and thus have no participation in international regimes or membership in international organizations. It should be worrying that the number of such 'states' has been on the rise for nearly three decades consecutively. It is understandable that no information is provided by such de facto states about their own armed forces or their activities. They are not participating states of the OSCE and have not taken part in the Vienna Document. It is a different matter when a participating state stations forces and conducts military activities on a 'de facto' state's territory and does not provide information about it. The problem then arises as to whether it is a non-compliance case or not, and whether it is in the area of application? For most participating states it is, as the territory legally belongs to another partici- 
pating state. For a minority of participating states it is not, as it is on the territory of a non-participating state.

In some cases, violations may reach the level of absurdity. For example, when a participating state does not provide notification of activities, that should be subject to notification, while it informs its own public about them by providing the media with numbers that leave no doubt about activities that should be subject to both notification and observation. Although such cases are not frequent, they are all the more regrettable.

Last, but not least, there are participating states that do not provide CSBMs with data on their armed forces. These participating states can be divided into two categories. There are small states with extremely limited state capacities, weak governance and poor organization that probably, incidentally, do not provide information when it is regularly required. But there can be others that systematically avoid providing information. Whereas in the case of the former, it would be difficult to attribute this behavior to concealment measures, in the case of the latter it may well be their intention to gain some marginal advantage from non-compliance.

\section{Compliance with the Open Skies Treaty}

Whereas in the area of CSBMs the West is perceived to be in the position of demandeur, compliance with the Open Skies Treaty presents a more complex picture. Once again most of the non-compliance issues are related to ongoing conflicts or the changing of hands of territories. With the latter, they are regarded as having arrived at a new status quo for some states but not for others, and therefore have unsettled territorial status of some parts of the treaty's area of application and the pending protracted conflicts.

Beginning with the purpose of the Open Skies Treaty, its objective is to provide for military transparency. Hampered by a history of using overflights for complementing information gained by other intelligence means (using U-2 flights, for example), some parties, understandably, want to exempt certain sensitive areas where overflights must not be allowed, should be restrained or the use of highest quality equipment/sensors ought to be curtailed.

Difficult relations generate the temptation to create complications in order to prevent the treaty from functioning properly. In some cases, states use the unregulated status of a territory to exempt it from overflights; in others, states argue on the basis of the 'independent statehood' of a territory, and so they impose technical conditions, which make full access to a territory impossible.

In case of the South Caucasus, the situation, with reference to separatist entities, is based on the claim that for one participating state (irrespective of which name the different participating states use) they are independent states, not participating states of the OSCE and not parties to the Open Skies Treaty either. As they are not parties to the Open Skies Treaty they must not be overflown. In accordance with the rules of the Treaty, their borders shall not be approached within ten kilometers. The disagreements over this matter are derived from the larger political issue of the 'independent statehood' of the two 
entities and can hence only be resolved by addressing the root cause. A state's reluctance to allow overflights by a participating treaty member that has been backing the independence of the two statelets since 2012 is one example ${ }^{13}$ and can be regarded as a counter-measure to the flight ban in the vicinity of their border.

The situation that has emerged since 2014 that allows scheduled flights of one state's air company to fly within the airspace of another does not prevent the parties conducting overflights under the Opens Skies Treaty. However, claims from one conflicting party for prepayment of the costs of the flights from the other is not in accord with the decision of the OSCC and is also an unfriendly gesture. Similarly, flights in the border area between a treaty party and its non-treaty party neighbor can be constrained and it will need the root cause of the problem to be addressed in order to overcome this difficulty. Conventional arms control treaties, including transparency measures, are really peacetime measures and are not meant for situations in which a part of the area of application of the treaty is a war zone.

Attempts to prevent the treaty from functioning as it was intended, are more conspicuous when a state has introduced regulations that prevent the overflight of a fully strategically sensitive area. Irrespective of whether the necessary information can be collected and verified by other means, it is not practical to accept this erosion of the treaty regime as it may serve as point of reference to undermine compliance further. The fact that there are no overflights conducted by NATO member-states among themselves curtails the access of other states to raw data among others. ${ }^{14}$ Again, it is the sovereign choice of members of an alliance to follow such practice, although there might be cases when reasons to reconsider it may prevail.

There are several technical issues that the state parties ought to discuss in order to find constructive solutions, if necessary, in the framework of classical tit-for-tat bargaining. These include the use of sensors in some areas, the technical conditions at certain airfields (apron, length of runways) and the number of permitted landings for refueling, for example. Although the violations may be numerous, none of them ought to cause existential security concerns.

\section{Conclusions}

After an interval of more than two decades, military security has returned to the political agenda in Europe. The illusion that many have pursued, that security is guaranteed for most European states, turned out to be unfounded and temporary. The revival of military security is at odds with an arms control regime that has not been successfully adjusted to the changes since the beginning of the post-Cold War era. Due to the unadjusted (and partly outlawed) arms control regime, violations of the letter of various accords have remained

13 Shakirov, "Kontrol' nad obychnymi vooruzheniyami v Evrope," 33.

14 Shakirov, "Kontrol'," 33. 
limited. Violations gain significance in conjunction with crises, real or potential, protracted conflicts and the strategic reassessment of the importance of certain areas in the application of the treaties. It is important to closely monitor the so-called 'norm challenging behavior' as it prepares for norm erosion and increases the danger of institutional decay. ${ }^{15}$ It is irresponsible to create a situation in which participating states or state parties could mutually refer to each other's violations of commitments. On a larger scale with respect to some major conflicts (Kosovo, Iraq, Georgia, Ukraine) this has been going on for nearly two decades without anybody providing reasons why one state's violation legitimizes that of another state or, to put it more bluntly: Why states have to follow each other into the mud.

In spite of the quest to make arms control measures not only applicable in fair weather, this request has remained only partially fulfilled. Some measures have been introduced in the CSBM packages of the early 1990s in order to address this matter. ${ }^{16}$ The measures have also been applied under stressful circumstances, like the so-called Kosovo war of 1999. Still, further measures may be necessary to advance the applicability of CSBMs in other difficult circumstances.

The current fora should be adequate to address compliance matters unless they are being obstructed by some participating states or state parties. However, because of their politicization, some fora (like the Forum for Security Cooperation (FSC) or the Open Skies Consultative Commission (OSCC)) are used for megaphone diplomacy in which delegates make statements and use harsh rhetoric in order to demonstrate their toughness to their own masters rather than conducting dialogue with their partners. This, inevitably, reduces the relevance and usefulness of these fora. Consequently, there are working bodies like debates on Open Skies in a smaller framework or the Structured Dialogue, which take the place of the larger fora. They function as genuinely multilateral fora even though NATO assembles 29 allied nations from among them. However, the expectation that the smaller members will simply accept positions about which large parties persuade them or which are imposed upon them by larger ones even when it is not in their national interests, reflects a way of thinking not shared by every participating state.

The current thresholds for notification and observation are too high and can be misused. The violation of their spirit can start by not providing sufficient transparency and then simultaneously mobilizing units for so-called snap exercises. It is understandable that some armed forces will have to catch up after a period in which they did not take training sufficiently seriously and did not allo-

15 Ulrich Kühn, "Cooperative Arms Control in Europe: The Consequences of Complexity, Decay, Power, and Norms" (Presentation to the Expert Roundtable on Conventional Arms Control and Confidence-Building Measures in Europe, OSCE Security Days, Vienna, November 10, 2014), 6.

16 "Vienna Document 1990," Organization for Security and Co-operation in Europe, November 17, 1990, Chap. III. 
cate adequate resources to defense, like the Russian Federation in the 1990s. However, providing information on a voluntary basis must be possible in order to alleviate concerns even if a new set of confidence- and security-building measures cannot be agreed upon. Such a step would be contingent upon an improved or at least more relaxed political atmosphere.

It is essential to see that some of the notification and observation measures were agreed as long ago as 1986 so that they would not be applicable to the then most frequent Warsaw Treaty exercises using mechanized divisions. Clearly, many of our concerns reappear faster and are more vivid when they are grounded in Cold War history. Diplomats need to know that analysts are well aware that the current heating up of tension, partially grounded in objective reality, is complemented by the fact that today's re-emerging adversary is a state that is often regarded as being identical with the old familiar Cold War adversary. It makes drawing conclusions rapid and simple without much consideration being given to the major differences between the two periods.

Arms control has changed a lot over the last decades in Europe. Still, there are matters in which no change is apparent. There are still participating states with significantly larger military capabilities than others. Although all regimes are required to meet the same normative obligations, the strategic importance of compliance focuses mainly on a few states. The agreements provide tools to observe eventual violations of one sort or another. However, there are difficulties in taking action in the light of detected violations. When Fred Ikle wrote his seminal article in $1961^{17}$ concerning the dilemma states were facing when they detected the violation of an arms control accord by a party whose participation was essential to the accord, he raised the ultimate question of what to do about the violator. What means the other parties have (not in the sense of international law as that is fairly clear) beyond publicly 'naming and shaming' the violator is open to conjecture. In the end, expelling the pivotal partner from the arrangement with reference to its massive or systematic violation does not solve the problem; it simply gives a free hand to the violator to get rid of the commitments that it was previously obligated to obey. Fortunately, there are no premeditated, concerted, large-scale, systematic violations of strategic significance nowadays and, hence, the unresolved dilemma is not high on the agenda of interested parties. This is the case even though some military experts and diplomats, for tactical reasons, may make attempts to portray the differences as strategic in the area of compliance with arms control.

It seems, under the current conditions, that there is no chance to negotiate new, substantive arms control measures. Even those initiatives that were put on the table have been taken back or meant more for strategic 'sondage' than anything else. It has usually been a question of whether there is a resolve to free some small area of conventional arms control from strategic counter-in-

17 Fred Charles Iklé, “After Detection - What?” Foreign Affairs 39, no. 2 (January 1961): 208-220. 
terest on a higher level. This would require visionary statesmen/women on a higher political level than the present managers and power perpetuating egoists. However, history never ends. If there is little chance for new arrangements to agree upon, states have to decide on what to do next by focusing on the process and leaving the outcomes for better times. It seems that what is being done is precisely what may help under the current conditions:

1. Not seeking to negotiate any new document on European arms control due to the unfavorable atmosphere and the conflicts that impose themselves on European security nowadays

2. Maintaining dialogue on a professional level to discuss items of relevance

3. Decoupling the process of forward looking considerations from some of those established frameworks (JCG, OSCC) that have lost some of their relevance as fora for professional exchange due to the historical burden of formal exchanges

4. Keeping watch on compliance in order to prevent further erosion and a growing irrelevance of the existing arms control regimes.

The lasting stalemate results in an increasingly busy expert community trying to address and contribute to its resolution. Most of their efforts will not bring about immediate results but may contribute to creating a depot of intellectual ammunition that can be explored when the opportunity arises.

It is essential to reassess the situation objectively and to conclude whether the overwhelmingly technical violations can be separated from the eventual strategic discord. It will also be essential to leave the professionals to gain more autonomy so that they can act in the best interests of their nations rather than having to meet the expectations of certain groups, which may wish to impose their ill-informed positions upon them.

\section{Disclaimer}

This paper is based on information in the public domain and on interviews with delegates of eight participating States who were kindly available during my visit to Vienna in July 2017. The asymmetry of publicly available information could influence the analysis. It goes without saying that the responsibility for the content rests with the author.

\section{About the Author}

Dr. Pal Dunay is Professor of NATO and European Security Issues at the Marshall Center and Academic Advisor of its Central Asia program, PASS, ESS-E, and SES courses. E-mail: pal.dunay@marshallcenter.org. 